\title{
PREDICTING WILDLIFE-VEHICLE COLLISIONS IN AN URBAN AREA BY THE EXAMPLE OF LUBLIN IN POLAND
}

\author{
TAJCHMAN, K. ${ }^{1}$ - GAWRYLUK, A. ${ }^{2 *}-$ FONSECA, C. $^{3}$ \\ ${ }^{I}$ Department of Animal Ethology and Wildlife Management, Faculty of Animal Sciences and \\ Bioeconomy, University of Life Sciences in Lublin, Lublin, Poland \\ (e-mail: katarzyna.tajchman@up.lublin.pl; phone: +48-81-445-6848) \\ ${ }^{2}$ Department of Grassland and Landscape Shaping, Faculty of Agrobioengineering, University \\ of Life Sciences in Lublin, Lublin, Poland \\ ${ }^{3}$ Department of Biology \& CESAM, University of Aveiro, Campus de Santiago, 3810-193 \\ Aveiro, Portugal \\ (e-mail: cfonseca@ua.pt; phone: +351-234-247-103) \\ *Corresponding author \\ e-mail: adam.gawryluk@up.lublin.pl; phone: +48-81-445-6994
}

(Received 20 $0^{\text {th }}$ Nov 2019; accepted $30^{\text {th }}$ Jan 2020)

\begin{abstract}
The aim of the study was to develop a new model for the prediction of wildlife-vehicle collisions (WVC) in urban areas, more specifically in the city of Lublin (Poland) and its surroundings. Prediction new model probability of WVC will be a valuable tool for city planners and will increase road safety for drivers and animals. The number of WVC was compared with data on traffic intensity in the same period, land use forms and seasons of the year. The data were analyzed statistically and the values of the parameters were presented as the mean value and standard error or standard deviation. Almost half (42.7\%) of the analyzed collisions took place on roads characterized by traffic that does not exceed 100 vehicles/day. The highest number of collisions with animals was reported in summer and spring, i.e. 91 and 78 events, respectively. There was also a highly significant positive correlation between the increase in the number of accidents with animals and the traffic intensity of 501-600 and 1101-1200 vehicles/day on the roads. The distances from river valleys, residential buildings, and industrial development turned out to be significant predictor variables for WVC.
\end{abstract}

Keywords: wildlife-vehicle collisions, models probability of collisions, urban area, traffic intensity, wild animals

\section{Introduction}

In the last decade, there has been a steady increase in the number of protected animal species (e.g. beaver by $76 \%$ ) and medium wild game (e.g. hare by $40 \%$ or pheasant by $13 \%$ ) in Poland, which is a positive phenomenon concerning the protection of biodiversity and genetic resources of populations of these species (GUS, 2010-2018). As shown by GUS data (2010-2018), the number of large game has increased (elk by $170 \%$, red deer by $50 \%$, roe deer by $12 \%$, and fallow deer by $2.5 \%$ ), which may have adverse consequences for both animals and humans. Animal overpopulation may lead to the reduction of the food base, which forces animals to migrate in search of better living areas and contributes to an increase in road events involving animals (Huijser et al., 2008; Tajchman et al., 2017A).

Wildlife-vehicle collisions (WVC) are one of the most widespread and persistent conflicts between humans and wildlife worldwide, especially since the increasing numbers of humans and animals inhabiting smaller areas (Huijser et al., 2009; Conover, 2010). In Poland and many other countries, it is very difficult to provide accurate data 
on road events with animals and their number is often underestimated because many collisions are not reported (Huijser et al., 2008; Snow et al., 2015).

In the Lublin region based on documentation data from the years 2011-2013 1073 deer-vehicle collisions occurred (Tajchman et al., 2017a), while in the city of Lublin in the period of 2009-2012 the number of incidents with wild animals was recorded to be 930 (Tajchman et al., 2017b). WVC are associated with financial consequences. In Poland, the cost of one collision with an animal was estimated at ca. 2144 USD; the cost of an accident resulting in human body injury is $7621 \mathrm{USD}$, and an accident with human casualties reaches 2692405 USD. The mean cost of the accidents in 2001-2010 was 45657961 USD. In Utah, the USA, the total cost of wildlife-vehicle collisions for the period of 1992-2001 was estimated at 470 million dollars (Tyburski and Czerniak, 2013). On average of São Paulo reported 2611 animal-vehicle crashes per year. The total annual cost to society was estimated at 25144794 USD. The average cost for an animal-vehicle crash, regardless of whether human injuries and fatalities occurred, was 9629 USD. The Brazilian legal system overwhelmingly (91.7\% of the cases) holds the road administrator liable for animal-vehicle collisions, both with wild and domestic species. On average, road administrators spent 1005051 USD per year compensating victims (Abra et al., 2019). Huijser et al. (2008) have shown that collisions with large animals, e.g. deer or elk, result in the highest number of injuries and fatalities in humans. It is estimated that property damages associated with collisions with ungulates reach 300 million USD per year in Canada and over 6 milliard USD per year in the USA (the average cost per event: 6717 USD). It has also been demonstrated that $90 \%$ of road collisions with cervids result in fatalities, and trauma is reported in 56-65\% of humans (Conover et al., 1995; Transport Canada, 2003; Huijser et al., 2009).

Attention should also be paid to other species of animals that fall victim to vehicle wheels as well. Such investigations are rarely conducted, as collisions with e.g. a fox or a mink do not usually cause large material loss, or the damage is invisible at first glance.

The presence of animals has been shown to be strongly correlated with the type and function of the habitat, proximity to resources (such as food or shelter), and the reason for the presence of the animal at the roadside (e.g. foraging or attempt to cross the road). The frequency of collisions is also correlated with the features of the road itself (width, curvature, and surface type), climatic conditions, road traffic intensity, and driver's condition (Ramp et al., 2006).

Currently, increasing numbers of animals move to cities or migrate through urban areas (Kalinowska, 2008). Despite the threats to biodiversity posed by living in the city, there are also many undeniable advantages (Wheater, 1999). An important factor ensuring favorable conditions of living in cities is the absence of hunting events or other forms elimination of species, especially large birds and mammals. In cities, which are inhabited by large numbers of people, there is always food available for animals, due to the presence of garbage containers, waste bins, or kitchen leftovers. More importantly, the food is available throughout the year. The city also provides regular access to water in park water reservoirs or decorative fountains. An advantage for many animal species living in urban areas is the milder winters (the average temperature in the city is higher by at least $1{ }^{\circ} \mathrm{C}$ ) (Wheater, 1999; Reichholf, 2009). All these factors promote animal migration to cities. The greater number of wild animals living in urban habitats is associated with an increased risk of animal-vehicle collisions, although the permissible speed of vehicles in built-up areas is $50 \mathrm{~km} / \mathrm{h}$ ( $\mathrm{Road}$ Traffic Department in Poland). 
Knowledge of the determinants of animal migration and identification of specific areas with a high risk of this type of accidents can improve drivers' safety on newly built road sections. Methods for mitigation of such conflicts (wildlife-human) are a current priority for both city authorities and handlers of wildlife (Found and Boyce, 2011).

Gunson et al. (2011) suggested a need for future research to be focused on modelling specific to each animal species and modelling the measurement of predictive power in specific areas so that the models can be used in similar landscapes. There are sparse investigations of wildlife-vehicle collisions in medium-sized cities. Therefore, the present study will fill the gap in data on such accidents in such agglomerations as Lublin. Road ecologists have analyzed the available georeferenced localizations of WVC to identify their distribution patterns along roads (Puglisi et al., 1974; Krisp and Durot, 2007; Ramp et al., 2005, 2006; Mountrakis and Gunson, 2009). These analyses have revealed that WVC along roads do not occur randomly but are spatially concentrated for specific vertebrate species, including ungulates (Puglisi et al., 1974; Hubbard et al., 2000; Joyce and Mahoney, 2001) and other species (Clevenger et al., 2003; Ramp et al., 2006). Therefore, an attempt was made to detect such areas in the city of Lublin and its surroundings.

\section{Material and methods}

\section{Study area}

Lublin is a city in the eastern part of Poland $\left(22^{\circ} 34^{\prime} \mathrm{E} 51^{\circ} 14^{\prime} \mathrm{N}\right)$ with an area of approx. $147 \mathrm{~km}^{2}$. Its area comprises 195.75 ha of parks and gardens, 1674.29 ha of forests (occupying $11.35 \%$ of the land), 5633 ha of agricultural land (38.2\%), including 4745 ha of arable land, 153 ha of orchards, and 452 ha of meadows and pastures, rivers (45.1 km long), and public roads $\left(317.4 \mathrm{~km} / 100 \mathrm{~km}^{2}\right)$. The city has 339850 inhabitants and the population density is 2305 people $/ \mathrm{km}^{2}$ (Study of conditions..., 2019). The mean annual air temperature in the city is $7.3^{\circ} \mathrm{C}$. The lowest average monthly temperature is noted in February $\left(-4.0^{\circ} \mathrm{C}\right)$ and the highest value is recorded in July $\left(18.2^{\circ} \mathrm{C}\right)$. Negative temperatures are recorded from December to March, whereas hot days with air temperatures above $25{ }^{\circ} \mathrm{C}$ occur from April to September. The mean annual precipitation sum in the city is approx. $560 \mathrm{~mm}$, with the highest values in July $(77.0 \mathrm{~mm})$ and the lowest in January $(29.6 \mathrm{~mm})$ (https://www.lublin.eu/mieszkancy/srodowisko/srodowisko-przyrodniczelublina/klimat/, Kłysik et al., 2008).

\section{Collision data}

The aim of the study was to carry out an analysis of wildlife-vehicle collisions in the area of Lublin city, Poland, between the beginning of December 2017 and the end of November 2018. Mutual correlations of the number of WVC with the traffic volume, land use, and seasons of the year were examined. Based on registered road events with wild animals, new models were developed to determine the risk of occurrence of collisions with wild animals in the city of Lublin. The animals were divided into large species (over $30 \mathrm{~kg}$ ): fallow deer (Dama dama), wildboar (Sus scrofa), red deer (Cervus elaphus) (Fig. 1), and roe deer (Capreolus capreolus); medium animals: European badger (Meles meles), European beaver (Castor fiber), domestic ferret (Mustela putoriusfuro), raccoon dog (Nyctereutes procyonoides), stone marten (Martes foina) 
(Fig. 2), red fox (Vulpes vulpes), European otter (Lutra lutra), brown hare (Lepus europaeus) and small: European hedgehog (Erinaceus europaeus), red squirrel (Sciurus vulgaris), etc., and other animal species.

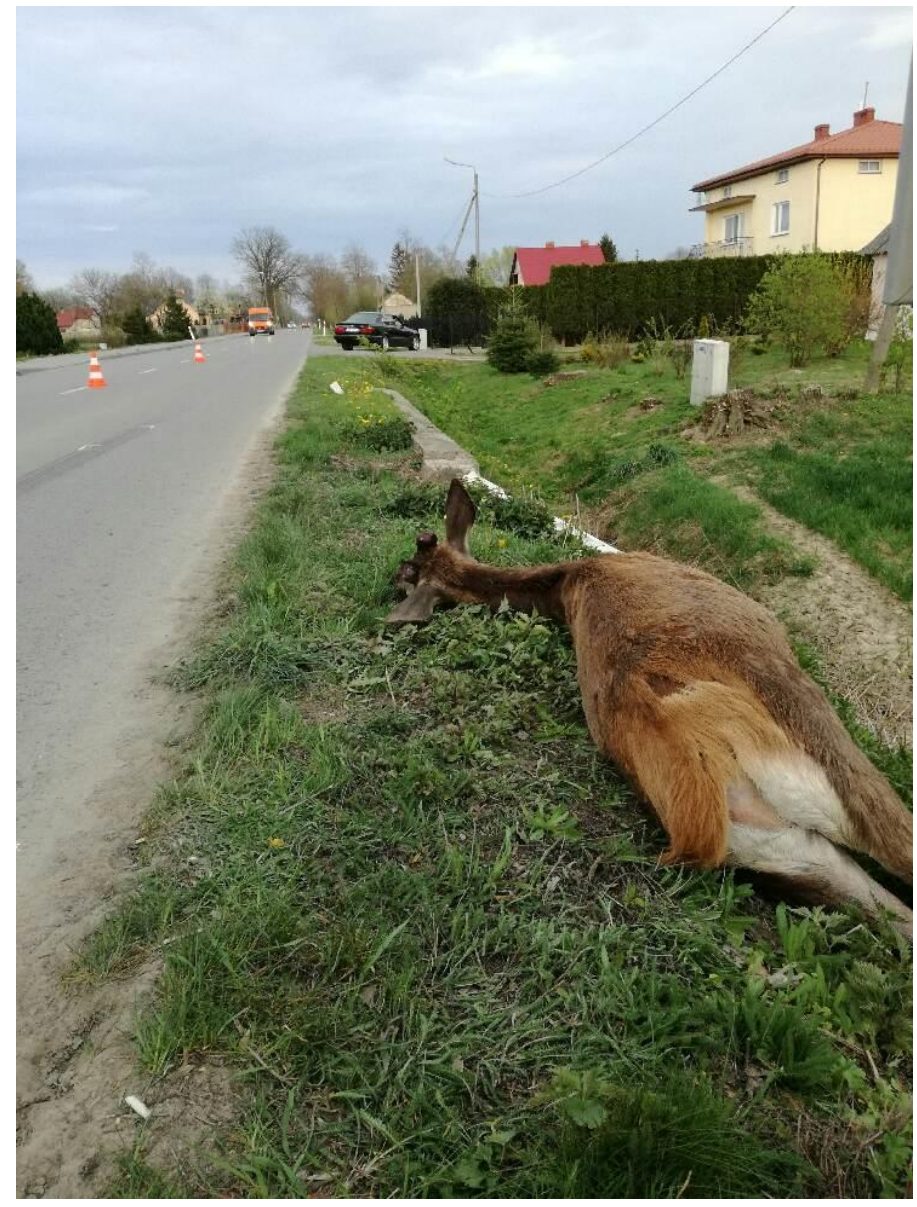

Figure 1. WVC with large animal (Cervus elaphus)

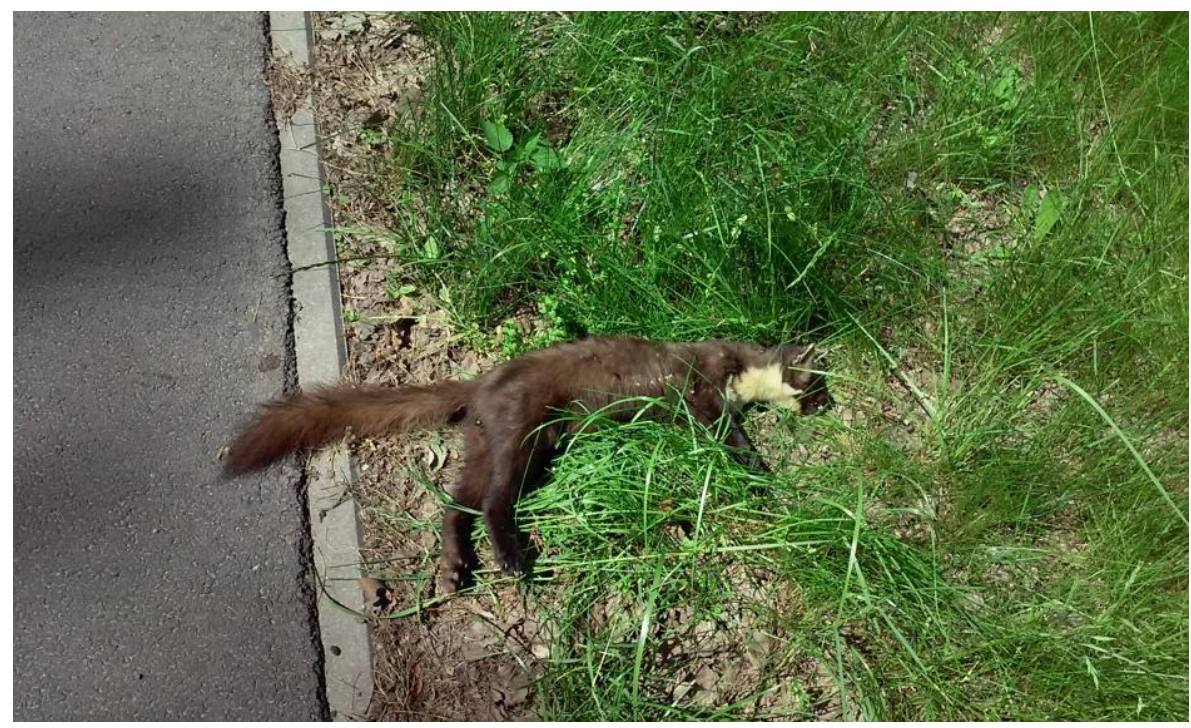

Figure 2. WVC with small animal (Martes foina) 
The data on wildlife-vehicle collisions in the city of Lublin they were collected from roads where there were no technical barriers. The information were reported to municipal services that arrive directly at the scene of the incident (to help injured animals and/or remove dead animals from the road). The collision sites were converted to GPS (Global Positioning System) coordinates with the use of a Hi-Target Qstar6 receiver with the accuracy of determination of a single point of $2.5 \mathrm{~m}$. Next, using Arc GIS Pro 2.0 software, they were transferred as vectors onto digital maps of Lublin at an accuracy level corresponding to scale 1: 50000.

\section{New landscape-based models and statistical analysis}

The number of WVC was compared with data on traffic intensity (vehicle/day) in the same period, land use forms (residential buildings, industrial development, urban greenery, river valleys, agricultural areas, and forests), and seasons of the year. The data were analyzed statistically and the values of the parameters were presented as the mean value and standard error or standard deviation.

It was assumed in the study that the registered WVC sites might be located at a considerable distance from the actual place of the event, as large animals (e.g. red deer) are able to cover even another $800 \mathrm{~m}$ after the accident (Found and Boyce, 2011; Finder et al., 1999). Therefore, buffers with a radius of $800 \mathrm{~m}$ were established in the sites of collision with large animals. To create a result map showing the impact of land use on the probability of wildlife-vehicle collisions, Lublin was divided into six forms of land use mentioned above, which were considered important from the point of view of landscape ecology by $\mathrm{Ng}$ et al. (2008).

The impact of land use on the probability of wildlife-vehicle collisions was assessed by mounting the layers of collision maps onto a map showing the selected forms of land use. Then, in each site of collision, the distance (in a straight line) from the nearest land use forms was determined. Knowing the lengths of the sections connecting the collision sites with the forms of land use and using logistic regression, the following new models of the probability of collisions with animals were proposed (Eq. l):

$$
\ln \left(\frac{p_{A}}{1-p_{A}}\right)=\alpha_{0}+\sum \alpha_{i} x_{i}
$$

where: In - natural logarithm function, $p_{A}$ - probability of collision, $x_{i}$ - predictor variables, $\alpha_{0}, \alpha_{i}$ - regression coefficients.

To develop new models for prediction of the risk of wildlife-vehicle collisions in the area of the city of Lublin and its surroundings, a random sample of points was determined for the location of roads (i.e. a land use form). The spatial data were processed in the ArcGIS for Desktop 10 environment. Next, to generate a grid of 300 objects, the Create Random Points tool, which is part of the data management tool set in the ArcToolbox application, was used. While generating the grid of objects, the minimum distance between two closest randomly designated points was assumed as $\geq 50 \mathrm{~m}$. Subsequently, the data were verified manually. Based on estimation of the regression coefficients and with the use of logistic regression, models were generated for prediction of the risk of collision with medium and small $(E q .4)\left(\mathrm{P}_{\mathrm{AS}}\right)$ and large animals $\left(E q\right.$. 3) $\left(\mathrm{P}_{\mathrm{AB}}\right)$, as well as all animals regardless of their size $(E q .2)\left(\mathrm{P}_{\mathrm{A}}\right)$. With the use of the ArcGIS tools, the model compliance with the actual data was $74.9 \%$, 
$77.8 \%$, and $73.5 \%$, respectively. The predictor variables and the transforming function are presented in Table 1.

Table 1. Marks of predictor variables and transforming function

\begin{tabular}{c|c|c}
\hline Prediction variable & Transformation & Designation \\
\hline Distance from river valleys & $\log _{10}(x+1)$ & LR \\
Distance from forests & $\log _{10}(x+1)$ & LF \\
Distance from public greenery & $\log _{10}(x+1)$ & LG \\
Distance from agricultural land & - & A \\
Distance to housing & $\log _{10}(x+1)$ & LH \\
Distance from industrial buildings & $\log _{10}(x+1)$ & LI \\
\hline
\end{tabular}

LR- distance from river valleys, LF- distance from forests, LG- distance from public greenery, Adistance from agricultural land, LH- distance to housing, LI- distance from industrial buildings

Model of risk of collision with all animal species:

$$
p_{A}=\frac{1}{1+\exp (0.3474 \cdot L R+1.0709 \cdot L H-1.1671 \cdot L I)}
$$

Model of risk of collision with large animals:

$$
p_{A B}=\frac{1}{1+\exp (0.4688 \cdot L R+1.2746 \cdot L H-1.2928 \cdot L I+0.00027 \cdot L F)}
$$

Model of risk of collision with medium and small animals:

$$
p_{A S}=\frac{1}{1+\exp (0.3797 \cdot L R+1.1130 \cdot L H-0.9798 \cdot L I)}
$$

where: LR- distance from river valleys, LH- distance to housing, LI- distance from industrial buildings, LF- distance from forests.

The statistical analyses of the probability of collision with medium and small animals were carried out at a significance level of $P=0.05$ in the Statistical Analysis System (SAS, 2012). Distances from river valleys (LR), forests (LF), urban greenery (LG), agricultural land (LA), residential buildings (LH), and industrial development (LI) were regarded as dependent variables. With the exception of the distance from forests, the variables were transformed by the decimal logarithm to reduce the skewness of the distribution of the distances to the analyzed areas (Zar, 2010). Additionally, mutual correlations (CORR procedure) between the variables were analyzed to eliminate the highly correlated ones (Zar, 2010). The variables were then used as predictor variables in the logistic regression model with the maximum likelihood method (LOGISTIC procedure) for the resulting binary variable, specifying whether a collision had occurred at a given point ( 1 - collision, 0 - no collision at a random point) (SAS, 2012). To develop the final model, we used a full model with all potential predictor variables and different modes of choice of only relevant variables: 
stepwise, forward, and backward elimination. The best model was selected using the Akaike information criterion, AIC (Akaike, 1974). To simplify the model, the interactions between the variables were disregarded. New models of the risk of wildlife-vehicle collisions were developed taking into account the division into large, medium, small, and all animal species.

Due to the large variability of the data in relation to the low number of collisions, a method used commonly in the case of concentration of events (hot spot analysis) had to be employed. It allows graphic representation of areas with high intensity of a given phenomenon (hot spot).

\section{Results}

The analyzed data showed that there were 291 collisions with animals in the city of Lublin and its surroundings during the study period, with almost half (42.7\%) taking place on roads where the traffic intensity did not exceed 100 vehicles/day, and the collisions with medium and small animals accounted for $57.9 \%$.

Areas especially susceptible to WVC (hot spots) in Lublin were identified where minimum two 800-meter buffers extending from the event sites overlapped (Fig. 3). The analyses demonstrated 105 hotspots in the area of Lublin, with more than half $(58.1 \%)$ of the sites where only two buffers overlapped. Three buffers overlapped in $28.6 \%$ of the hot spots. In turn, $8.6 \%$ of the hot spots were located in sites with 4 overlapping buffers. Only $2.9 \%$ of and $1.9 \%$ the hot spots comprised 5 and 6 overlapping buffers, respectively (Fig. 3). The hot spots of collisions with large animals were located mainly in the areas of urban greenery (40.0\%), agricultural land $(20.0 \%)$, and forests $(15.4 \%)$. In turn, the other collision hot spots were located near residential buildings $(18.5 \%)$, industrial development $(4.6 \%)$, and river valleys $(1.5 \%)$. The vast majority $(83.8 \%)$ of the hot spots of collisions with large animals were located on the outskirts of the city, along the main communication routes leading to the city center (Fig. 3).

The results of the analysis of the correlation between the traffic volume (vehicles/day) and the number of road collisions with wild animals revealed significant relationships between these factors (Table 2). There was no significant correlation between the increase in the number of wildlife-vehicle collisions and the increase in traffic intensity in any of the analyzed cases of events with large animals. An exception was the road sections with traffic intensity of 501-600 and 1101-1200 vehicles/day, where a highly significant positive correlation of the increase in the number of WVC with the increase in traffic intensity was demonstrated $(R=0.4779$ and $R=0.3589$, respectively). Similarly, in the case of collisions with medium and small animals, no significant positive correlations were found between the number of events and the increase in traffic intensity. However, there was a significant negative correlation $(R=-0.2774)$ between the number of WVC and the increase in traffic volume on road sections exhibiting traffic intensity of 1101-1200 vehicles/day. This indicates that higher traffic intensity is correlated with a lower number of WVC (Table 2).

The analysis of the traffic intensity (vehicles/day) and the number of road collisions (regardless of the animal species) revealed a very strong negative correlation $(R=-0.3384)$ between the number of WVC and the increase in traffic intensity on road sections with traffic intensity of 301-400 vehicles/day (Table 2). 
This indicates a significant decline in the number of collisions with animals at a higher traffic volume. In turn, there was a significant positive correlation between the number of WVC and the increase in traffic in the case of roads with 501-600 vehicles/day $(R=0.2675)$. Compared to the former correlation, this relationship is weaker but justified by the considerably lower impact of traffic on the number of wildlife-vehicle collisions.

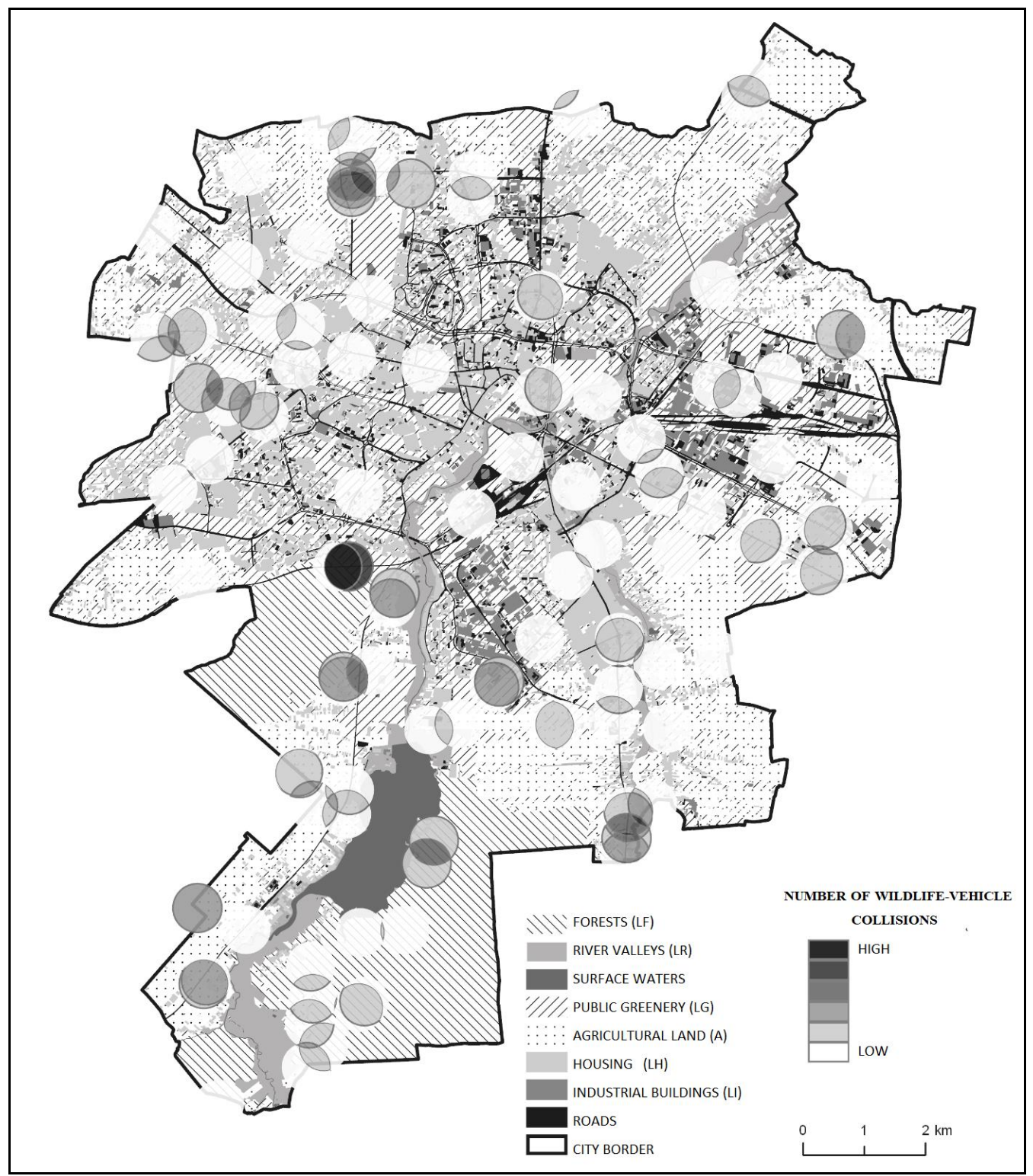

Figure 3. Location and number of collisions (hot spot) with large animals in the city of Lublin

No statistically significant correlation between the number of collisions and the season of the year was noted during the investigation period in the analysed area (Lublin). The highest number of WVC was recorded in summer and spring, i.e. 91 and 78 events with animals, respectively, which accounted for more than half $(58.07 \%)$ of all recorded collisions (Table 3). The highest number of single collisions (79) and double collisions (two accidents in one place) was found for 12 city points in summer. 
Also in spring, the vast majority of events were single collisions (68), double collisions took place in 8 city areas, and triple collisions were found in 2 city points; they constituted $87.18 \%, 10.26 \%$, and $2.56 \%$, respectively, of all collisions recorded at this time of the year (Table 3). In autumn, the vast majority of collisions $(88.41 \%)$ were single collisions (68). Double collisions in autumn were recorded in 7 points of the city $(10.14 \%)$. In the same season, 5 collisions were reported from 1 site in the city, which constituted $1.45 \%$ of all events recorded at this time of the year. The smallest number of wildlife-vehicle collisions, i.e. 53, which accounted for $18.21 \%$ of all collisions recorded in the investigation period, occurred in winter. As in the other seasons, the vast majority of collisions $(96.23 \%)$ in this period were single events, while double events occurred only in two city locations (Table 3).

No significant correlations were found between the WVC and the forms of land use in any of the analyzed cases. The highest correlation was determined for forests and arable land $(R=0.31)$ and there was a negative correlation between arable land and industrial development $(R=-0.36)$. In the case of large, medium, small, and all animals, models comprising only significant predictor variables were the best according to the AIC criterion. All methods for selection of the variables (stepwise, forward, backward) yielded the same models.

Regardless of the animal species, the distances from river valleys, residential buildings, and industrial development turned out to be significant predictor variables (Table 4). In the case of the first two variables, the risk of WVC increased with their decreasing value, while the risk of collision in the industrial development increased with the increasing distance from such areas.

Table 2. Relationship between wildlife-vehicle collisions (WVC) and intensity of traffic road (for $P>0.05)$

\begin{tabular}{|c|c|c|c|c|c|c|}
\hline \multirow{2}{*}{$\begin{array}{l}\text { Traffic intensity } \\
\text { (vehicles/day) }\end{array}$} & \multicolumn{4}{|c|}{ WVC } & \multirow{2}{*}{$\begin{array}{l}\text { Regardless of } \\
\text { the species }\end{array}$} & \multirow[b]{2}{*}{ SD } \\
\hline & Large animals & SD & $\begin{array}{c}\text { Medium and } \\
\text { small animals }\end{array}$ & SD & & \\
\hline$<100$ & 0.2618 & \pm 0.45 & 0.0900 & \pm 0.28 & 0.0802 & \pm 0.24 \\
\hline $100-200$ & -0.1995 & \pm 0.49 & -0.01855 & \pm 0.35 & -0.1827 & \pm 0.40 \\
\hline $201-300$ & -0.0971 & \pm 1.15 & 0 & \pm 0.00 & -0.1978 & \pm 0.79 \\
\hline $301-400$ & 0 & \pm 0.00 & 0 & \pm 0.49 & $-0.3384 * *$ & \pm 0.43 \\
\hline $401-500$ & 0.0290 & \pm 0.36 & -0.1676 & \pm 0.25 & -0.812 & \pm 0.30 \\
\hline $501-600$ & $0.4779 * *$ & \pm 0.25 & 0 & \pm 0.00 & $0.2675 * *$ & \pm 0.21 \\
\hline $601-700$ & -0.1526 & \pm 0.31 & -0.2244 & \pm 0.68 & -0.2131 & \pm 0.54 \\
\hline $701-800$ & 0 & \pm 0.00 & 0.0857 & \pm 0.40 & 0.0662 & \pm 0.31 \\
\hline $801-900$ & 0 & \pm 0.00 & 0.1162 & \pm 0.35 & 0.1037 & \pm 0.28 \\
\hline $901-1000$ & 0 & \pm 0.00 & 0 & \pm 0.00 & 0 & \pm 0.00 \\
\hline $1001-1100$ & 0 & \pm 0.00 & 0 & \pm 0.00 & 0 & \pm 0.00 \\
\hline $1101-1200$ & $0.3589 * *$ & \pm 0.28 & $-0.2774 *$ & \pm 0.33 & 0.1816 & \pm 0.30 \\
\hline $1201-1300$ & 0 & \pm 0.00 & 0 & \pm 0.00 & 0 & \pm 0.00 \\
\hline $1301-1400$ & 0 & \pm 0.00 & 0 & \pm 0.00 & 0 & \pm 0.00 \\
\hline $1501-2,000$ & 0 & \pm 0.00 & 0 & \pm 0.00 & 0 & \pm 0.50 \\
\hline$>2000$ & 0 & \pm 0.00 & 0 & \pm 0.46 & 0 & \pm 0.00 \\
\hline
\end{tabular}

SD - standard deviation, *significant dependence, **very strong dependence 
Table 3. Dependence of wildlife-vehicle collisions (WVC) quantity distributions from seasons (for $P>0.05$ )

\begin{tabular}{|c|c|c|c|c|c|c|}
\hline \multirow{2}{*}{ Seasons } & \multirow{2}{*}{$\begin{array}{l}\text { WVC depending on location and } \\
\text { season }\end{array}$} & \multicolumn{4}{|c|}{ Number of WVC in a given place } & \multirow{2}{*}{ Total } \\
\hline & & 1 & 2 & 3 & 5 & \\
\hline \multirow{4}{*}{ Autumn } & WVC number & 61 & 7 & 0 & 1 & 69 \\
\hline & Percent of WVC in a given place \% & 23.55 & 24.14 & 0 & 100.00 & \\
\hline & Percentage of WVC in a given season $\%$ & 88.41 & 10.14 & 0 & 1.45 & 23.71 \\
\hline & WVC percent of the full year $\%$ & 20.96 & 2.41 & 0 & 0.34 & \\
\hline \multirow{4}{*}{ Summer } & WVC number & 79 & 12 & 0 & 0 & 91 \\
\hline & Percent of WVC in a given place $\%$ & 30.50 & 41.38 & 0 & 0 & \\
\hline & Percentage WVC in a given season \% & 86.81 & 13.19 & 0 & 0 & 31.27 \\
\hline & WVC percent of the full year $\%$ & 27.15 & 4.12 & 0 & 0 & \\
\hline \multirow{4}{*}{ Spring } & WVC number & 68 & 8 & 2 & 0 & 78 \\
\hline & Percent of WVC in a given place $\%$ & 26.25 & 27.59 & 100.00 & 0 & \\
\hline & Percentage WVC in a given season $\%$ & 87.18 & 10.26 & 2.56 & 0 & 26.80 \\
\hline & WVC percent of the full year $\%$ & 23.37 & 2.75 & 0.69 & 0 & \\
\hline \multirow{4}{*}{ Winter } & WVC number & 51 & 2 & 0 & 0 & 53 \\
\hline & Percent of WVC in a given place $\%$ & 19.69 & 6.90 & 0 & 0 & \\
\hline & Percentage WVC in a given season $\%$ & 96.23 & 3.77 & 0 & 0 & 18.21 \\
\hline & WVC percent of the full year $\%$ & 17.53 & 0.69 & 0 & 0 & \\
\hline \multirow{2}{*}{ Total } & WVC number & 259 & 29 & 2 & 1 & 291 \\
\hline & WVC percent of the full year $\%$ & 89.00 & 9.97 & 0.69 & 0.34 & 291 \\
\hline
\end{tabular}

Table 4. Estimators of regression coefficients and their statistical significance for all animals

\begin{tabular}{c|c|c|c|c|c}
\hline Parameter & DF & Estimate & SE & Wald chi-square & P-value \\
\hline \multicolumn{7}{c}{ All animals } \\
\hline LR & 1 & -0.347 & 0.094 & 13.656 & 0.0002 \\
LH & 1 & -1.071 & 0.134 & 64.348 & $<0.0001$ \\
LI & 1 & 1.167 & 0.142 & 67.361 & $<0.0001$ \\
\hline \multicolumn{7}{c}{ Large animals } \\
\hline LF & 1 & -0.0003 & 0.0001 & 6.868 & 0.0090 \\
LR & 1 & -0.4690 & 0.1480 & 9.999 & 0.0020 \\
LH & 1 & -1.2750 & 0.1830 & 48.324 & $<0.0001$ \\
LI & 1 & 1.2930 & 0.1950 & 44.004 & $<.0001$ \\
\hline \multicolumn{7}{l}{ Medium and small animals } \\
LR & 1 & -0.379 & 0.109 & 12.251 & 0.0005 \\
LI & 1 & -1.113 & 0.153 & 52.669 & $<0.0001$ \\
\end{tabular}

DF- degrees of freedom used in the Wald-chi-square test, SE- Standard prediction error of the estimator (regression coefficient), Wald Chi-Square - Wald Chi-Square test values, P-value - the assumed level of significance of the test. P-value less than 0.05 (assumed test significance level) specifies that the given parameter is significant in the model (significantly different from 0), LR- distance from river valleys, LH- distance to housing, LI- distance from industrial buildings, LF- distance from forests 
In the analysis of collisions with large animals only, the variables indicated for all animals (distances from river valleys, residential buildings, and industrial development) and additionally the distance from forests (Table 4), for which it was found that the closer the distance to the forest the greater the risk of collision with large animals, turned out to be significant predictor variables. For the other predictor variables, the trend in the impact was similar to that in the case of all animals. While assessing the risk of collision with medium and small animals, the variables indicated for all animals, i.e. the distances from river valleys, residential buildings, and industrial development turned out to be significant predictor variables (Table 4). They had a similar effect to that noted in the analysis of all animals. The estimation of the probability of WVC shows the highest risk of such events in areas located on the outskirts of Lublin (Southern, South-eastern and north-western parts) (Figs. 4-5). A high risk of accidents with wild animals has also been identified for residential areas adjacent to the Bystrzyca and Czerniejówka river valleys in the central part of Lublin. The smallest risk of WVC was indicated near the industrial areas in the north and south of Lublin.

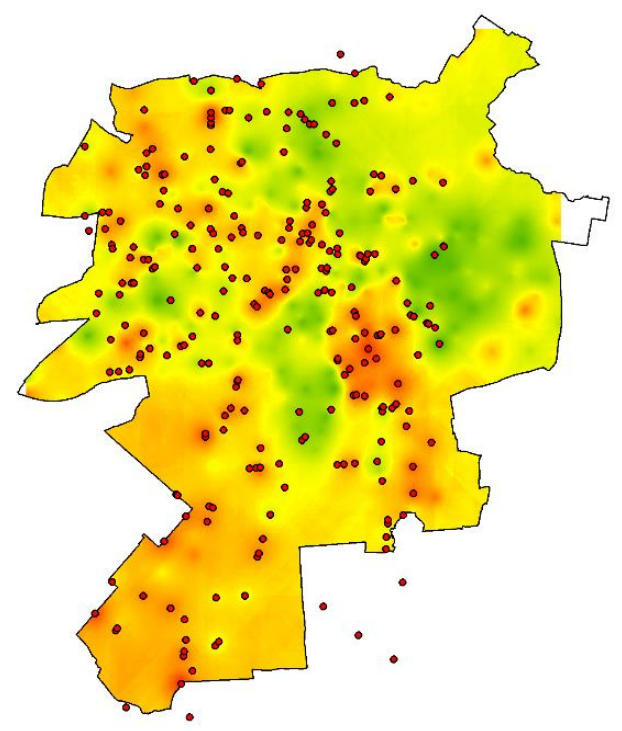

Figure 4. The probability of an accident with wild animals, regardless of the species, in Lublin (red color - high probability, green - low probability)

The analysis of the probability of collisions with animals indicates the greatest risk of collisions with large animals in an area located to the south-east from the center of Lublin (area adjacent to the Czerniejówka River valley) (Fig. 5A). It is a part of the city with compact single-family residential buildings with house gardens. A high risk of collisions with large animals has been noted in the southern part of Lublin, i.e. in the area of a large water reservoir (Zemborzycki Lake) surrounded by a forest complex, and in the central part - in a large city park (Ludowy Park) situated in the Bystrzyca River valley. As demonstrated by the analyses, areas located near the industrial development located in the northern, central, and southern parts of Lublin exhibit the lowest risk of collisions with large animals. 


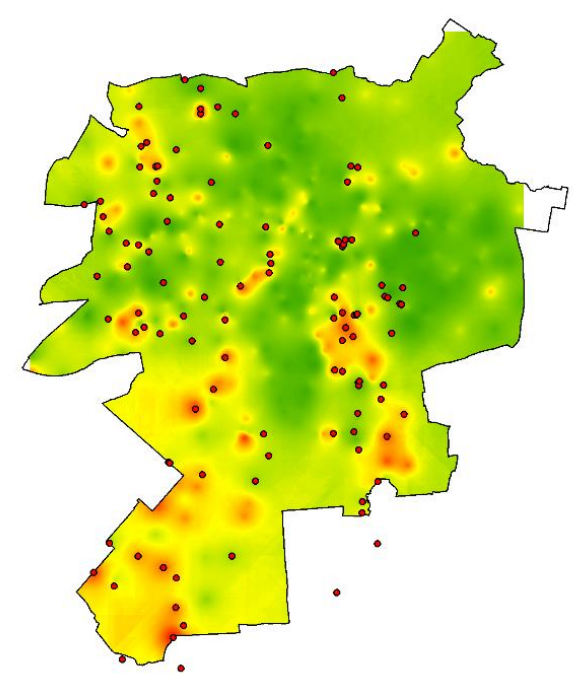

A

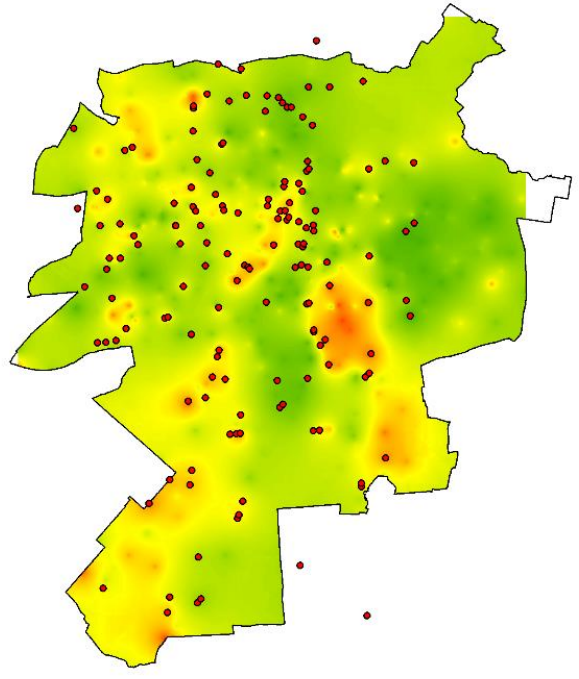

B

Figure 5. Maps of probability of collisions with animals in Lublin: A - with large animals, $B$ with medium and small animals (red color - high probability, green - low probability)

The highest probability of collisions with medium and small animals was shown for the south-eastern part of Lublin (Fig. 5B). This is probably related to the presence of residential buildings and the Czermiejówka River valley. Other areas with a high probability of collisions with medium and small animals are located in the central and north-western part of the city. The central part of the city comprises residential buildings located in the immediate vicinity of dry loess gorges serving as a city park. In turn, the area located in the north-western part of the city is the Czechówka River valley near a two-lane express road (Fig. 5B). As in the case of large animals, a high risk of collisions with medium and small animals was estimated for the southern part of Lublin around the water reservoir (Zemborzycki Lake) and for areas to the north and south of the lake located near the wetlands of the Bystrzyca River valley, which flows out of this water body. Areas with the lowest risk of collision with medium and small animals, as in the case of large animals, are located in industrial development areas in the northern, central, and southern parts of Lublin.

\section{Discussion}

The present investigations have demonstrated that the number of WVC decreases with the increase of traffic intensity. This is consisted with the results reported by Forman and Alexander (1998), who showed a road avoidance effect. Busy roads sometimes deter animals sufficiently to prevent them from crossing (Clevenger et al., 2003); thus, animal mortality declines. The exceptions were road sections with traffic intensity of 501-600 and 1101-1200 vehicles/day, where there was a highly significant positive correlation between the increase in the number of WVC and the increase in traffic volume. This may be associated with the substantially higher speed of driving on these roads, and traffic intensity and speed are the main factors WVC, as shown in many studies (Forman and Alexander, 1998; Hubbard et al., 2000; Jones, 2000; Trombulak and Frissell, 2000; Dique et al., 2003; Seiler, 2003). 
In the analyzed data from in the city of Lublin and its surroundings during the study period, there were no high correlations between WVC and land use forms. The sites of concentration of collisions with large animals (hot spots) were located mostly in the areas of urban greenery, agricultural land, and forest. This was confirmed in studies conducted by other authors (Hubbard et al., 2000; Nielsen et al., 2003; Farrell and Tappe, 2007; Ng et al., 2008), who found that wooded and open areas were the most attractive foraging sites for deer. The vast majority of sites of concentration of hot spots were located on the outskirts of the city along major communication routes leading to the city center. As demonstrated by Premo and Rogers (2001), there was an increase in collisions with deer in suburban areas.

The present study also showed the highest positive correlation between forests and arable land and a negative correlation between arable land and industrial development. These results are in agreement with those reported by Stewart et al. (2007) as well as Farrell and Tappe (2007), who have shown that cervids choose clearings with adjacent wooded areas and completely forested areas. The presence of open land near forested areas together with higher vehicle speeds and higher traffic volumes has been correlated with higher frequencies of deer-vehicle collisions (Bashore et al., 1985; Nielsen et al., 2003; Ng et al., 2008; McShea et al., 2008).

The analysis carried out in the city of Lublin and its surroundings shows the highest number of WVC in summer and spring. This is probably associated with the duration of the day and the seasonal activity of the animals. For many species of animals, spring is a time of reproduction, establishment of home ranges, fights for females, search for breeding places, and migration over distances larger than usual. Spring and summer are seasons when roebucks show increased activity establishing and protecting their territory (Ignatavicius and Valskys, 2018). In medium animals, e.g. fox and marten, this is a period of development of offspring and increased activity of females questing for food for their young ones (Goszczyński, 1995; Goszczyński et al., 1994; Herr, 2008). Interestingly, many studies indicate that autumn is another period (besides spring) with the highest number of accidents (39\%). This season is a time of migrations to wintering grounds and mating in some species (especially deer). In this period, males are particularly vulnerable to the risk of road collision, as they expand their territories in search and fight for females (Tajchman et al., 2017A). Researchers agree that, despite the increased frequency of road collisions with ungulates in Europe and the United States in recent years, the events are not associated with the threat of extinction of species involved. It is prevented by the high reproduction rate of these species and/or the high ability to re-colonise habitats where the population has gone extinct (Found and Boyce, 2011; Hubbard et al., 2000).

The investigations studies carried out in the city of Lublin and its surroundings demonstrate that most of WVC cases involve medium and small animals (57.9\%), with the greatest number of the events recorded in spring and summer. This phenomenon is disturbing, as the group of small animals often comprises species with small population sizes. Surveys carried out in Poland and Sweden (Seiler, 2004; Seiler et al., 2004) have shown that the brown hare is characterized by the highest rate of fatalities on the roads. It has been estimated that $35 \%$ of the 200,000 population of hares in Sweden dye in wildlife-vehicle collisions. The survival of populations of this species is also threatened in the Netherlands and Denmark, and mortality associated with collisions with motor vehicles may turn out to be an increasingly important factor limiting the population size of this species, which is endangered also in Poland. In the case of rare and endangered 
species, each individual dying under car wheels is a big loss. Quick recognition of the problem and mitigation actions can improve the status of the population. Intensive work is carried out to reduce otter mortality on the roads in Denmark and the death rate of the badger, i.e. a species threatened with extinction and decimated in wildlife-vehicle collisions, in the Netherlands (Lankester et al., 1991). Special attention should therefore be paid to this group of animals. In the present study, the risk of collisions with medium and small animals increased with the proximity to open water bodies or wetlands adjacent to roads (Gunson et al., 2011). This is in agreement with the results reported by Kanda et al. (2006), who noted collisions with small and medium vertebrates at low altitudes, which most likely provide favorable habitats for these animal species. The opposite was found for areas with higher road and building density (Bashore et al., 1985; Nielsen et al., 2003; $\mathrm{Ng}$ et al., 2008; McShea et al., 2008), which was also confirmed by the analyses carried out in Lublin. Interestingly, the present study has shown an increase in the number of WVC farther away from industrial development. This may be related to the fact that such facilities are most often located on the outskirts of the city, i.e. in open areas where animals dwell eagerly and humans are present only during working hours.

In the research carried out by Found and Boyce (2011) in the city of Edmonton, modelling was performed only for road collisions with cervids. It was demonstrated that the density of vegetation was by $52 \%$ higher in the established hot spots than in cold spots; additionally, the percentage of habitats available for animals was by $21 \%$ higher. This was also confirmed in the investigations conducted in Lublin showing that a closer distance to the forest was associated with a greater the risk of collisions with large animals. It should be remembered that increasing density of high vegetation causes poorer visibility and thus raises the risk of WVC due to the shorter time between noticing the animal and driver's reaction, which also increases the risk of WVC (Found and Boyce, 2011). Malo et al. (2004) emphasized that vegetation should be mown regularly within 40-80 m roadside buffers, which could lower the attractiveness of roadsides to herbivores. However, other studies have demonstrated that enlargement of the road width and visibility in roadside corridors increases the rate of WVC, as drivers move at higher speeds in such conditions. Another effective solution is the use of barriers or protective fences (Gunson et al., 2011).

\section{Conclusion}

Reliable and effective methods for WVC prediction and mitigation have become a priority for various city planners and wildlife handlers (Farrell and Tappe, 2007). Hence, similar studies should be carried out in all European cities with focus on the causes of the increased rates of wildlife-vehicle collisions. The existing WVC probability models should be used for graphic design - city maps with accident locations - hot spots. In addition, WVC probability models with individual groups of animals with similar biology and behavior should be constructed. This should be preceded by a thorough analysis of the number of WVC with large, medium and small animals. In aim of quick recognition of the problem and introduce mitigation actions which can improve the status of the animal population.

The distances from river valleys, residential buildings, and industrial development turned out to be significant predictor variables for WVCs. In the analysis of collisions with large animals, the variables were found that the closer the distance to the forest the 
greater the risk of collision increases. While assessing the risk of collision with small animals, the variables: the distances from river valleys, residential buildings, and industrial development turned out to be significant predictor variables. The highest number of WVC was recorded in summer and spring, which accounted for more than half $(58.07 \%)$ of all recorded collisions. When planning the expansion of cities, pay special attention to the listed places, which depend on WVC, with particular regard to animal species or their groups using available minimizing solutions.

Moreover, migrating animals tend to take the easiest paths (Boone et al., 1996; Schippers et al., 1996; Larkin et al., 2004); hence, the risk of WVC increases when roads are situated at the ground level (Clevenger et al., 2003; Malo et al., 2004; Ramp et al., 2005). Such areas are found in most parts of Lublin. Roads run along embankments and are additionally fenced with acoustic screens preventing free migration of wild animals only in the northern part of Lublin. These are pilot studies, therefore in the future, it is worth investigating the number of WVC in correlation with the terrain level and the location of roads. In addition, human factors/behavior and weather conditions should also be taken into account.

\section{REFERENCES}

[1] Abra, F. D., Granziera, B. M., Huijser, M. P., Ferraz, K. M., Haddad, C. M., Paolino, R. M. (2019): Pay or prevent? Human safety, costs to society and legal perspectives on animal-vehicle collisions in São Paulo state, Brazil. - PLoS ONE 14(4): e0215152.

[2] Akaike, H. (1974): A new look at the statistical model identification - IEEE Trans. Auto. Control. 19: 716-723.

[3] Bashore, T. L., Tzilkowski, W. M., Bellis, E. D. (1985): Analysis of deer-vehicle collision sites in Pennsylvania, USA - Journal of Wildlife Management 49: 770-774.

[4] Boone, R. B., Hunter, M. L., Cook, I. J. (1996): Using diffusion models to simulate the effects of land use on grizzly bear dispersal in the Rocky Mountains - Landscape Ecology 11: 51-64.

[5] Clevenger, A. P., Chruszcz, B., Gunson, K. E. (2003): Spatial patterns and factors influencing small vertebrate fauna road-kill aggregations - Biology Conservation 109: $15-26$.

[6] Conover, M. R. (2010): Resolving Human-Wildlife Conflicts: The Science of Wildlife Damage Management. - CRC Press, Boca Raton, FL.

[7] Conover, M. R., Pitt, W. C., Kessler, K. K., DuBow, T. J., Sanborn, W. A. (1995): Review of human injuries, illnesses, and economic losses caused by wildlife in the United States - Wildlife Society Bulletin 23: 407-414.

[8] Dique, D. S., Thompson, J., Preece, H. J., Penfold, G. C., de Villiers, D. L., Leslie, R. S. (2003): Koala mortality on roads in south-east Queensland: the koala speed-zone trial Wildlife Research 30: 419-426.

[9] Farrell, M. C., Tappe, P. A. (2007): County-level factors contributing to deer-vehicle collisions in Arkansas - Journal of Wildlife Management 71: 2727-2731.

[10] Finder, R. A., Roseberry, J. L., Woolf, A. (1999): Site and landscape conditions at whitetailed deer/vehicle collision locations in Illinois - Landscape and Urban Planning 44: 7785.

[11] Forman, R. T. T., Alexander, L. E. (1998): Roads and their major ecological effects Annual Review of Ecology and Systematic 29: 207-231.

[12] Found, R., Boyce, M. S. (2011): Predicting deer-vehicle collisions in an urban area. Journal of Environmental Management 92(2011): 2486-2493. 
[13] Goszczyński, J. (1995): Fox - Monograph Natural and Hunting. - Publishing House Oikos Sp. Z O. O., Warsaw (in Polish).

[14] Goszczyński, J., Romanowski, J., Zalewski, A. (1994): Martens. - Publishing Editorial Publishing World, Warsaw (in Polish).

[15] Gunson, K. E., Muntrakis, G., Quackenbsh, L. J. (2011): Spatial wildlife-vehicle collision models: A review of current work and its application to transportation mitigation projects - Journal of Environmental Management 92: 1074-1082.

[16] GUS 2001-2018 www.stat.gov.pl (access July 15, 2019).

[17] Herr, J. (2008): Ecology and behaviour of urban stone martens (Martes foina) in Luxembourg. - University of Sussex, Brighton (PhD thesis).

[18] https://www.lublin.eu/mieszkancy/srodowisko/srodowisko-przyrodnicze-lublina/klimat/ (access July 15, 2019).

[19] Hubbard, M. W., Danielson, B. J., Schmitz, R. A. (2000): Factors influencing the location of deer-vehicle accidents in Iowa - Journal of Wildlife Management 64: 707-712.

[20] Huijser, M. P., Duffield, J. W., Clevenger, A. P., Ament, R. J., McGowen, P. T. (2009): Cost benefit analyses of mitigation measures aimed at reducing collisions with large ungulates in the United States and Canada: a decision support tool - Ecology and Society 14(2): 15-22.

[21] Huijser, M. P., McGowen, P. T., Fuller, J., Hardy, A., Kociolek, A. (2008): WildlifeVehicle Collision Reduction Study: Report to Congress. - U.S. Department of Transportation, Federal Highway Administration, Washington.

[22] Ignatavicius, G., Valskys, V. (2018): The influence of time factors on the dynamics of roe deer collisions with vehicles - Landscape and Ecology Engineering 14(2): 221-229.

[23] Jones, M. E. (2000): Road upgrade, road mortality and remedial measures: impacts on a population of eastern quolls and Tasmanian devils - Wildlife Research 27: 289-296.

[24] Joyce, T. L., Mahoney, S. P. (2001): Spatial and temporal distributions of moose-vehicle collisions in Newfoundland - Wildlife Society Bulletin 29: 281-291.

[25] Kalinowska, A. (2008): Climate change - current and predictable impact on biodiversity in Poland and in the world. - In: Climate Change and Nature Protection - VI Kampinos Meetings with Nature. Conference Materials April 16, 2008, Kampinos National Park. Foundation of the Ecological Education Center, Warsaw, pp. 1-6.

[26] Kanda, L. L., Fuller, T. K., Sievert, P. R. (2006): Landscape associations of road-killed virginia possums (Diderphis virginiana) in Central Massachusetts - The American Midland Naturalist 156: 128-134.

[27] Kłysik, K., Wibig, J., Fortuniak, K. (2008): Climate and bioclimate of cities - University of Lodz Publishing, Łódź (in Polish).

[28] Krisp, J. M., Durot, S. (2007): Segmentation of lines based on point densities-An optimization of wildlife warning sign placement in southern Finland - Accident Analysis and Prevention 39: 38-46.

[29] Lankester, K., van Apeldoorn, R. C., Meelis, E. i Verboom, J. (1991): Management perspectives for populations of the Eurasian badger (Meles meles) in a fragmented landscape - J. Applied Ecology 28: 561-573.

[30] Larkin, J. L., Maehr, D. S., Hoctor, T. S., Orlando, M. A., Whitney, K. (2004): Landscape linkages and conservation planning for the black bear in west-central Florida - Animal Conservation 7: 23-34.

[31] Malo, J. E., Suarez, F., Diez, A. (2004): Can we mitigate animal-vehicle accidents using predictive models? - Journal of Applied Ecology 41: 701-710.

[32] McShea, W. J., Stewart, C. M., Kearns, L. J., Liccioli, S., Kocka, D. (2008): Factors affecting autumn deer-vehicle collisions in a rural Virginia county - Human-Wildlife Interactions 2: 110-121.

[33] Mountrakis, G., Gunson, K. E. (2009): Multi-scale spatiotemporal analyses of moose vehicle collisions: a case study in northern Vermont - International Journal of Geographical Information System 23: 1389-1412. 
[34] Ng, J. W., Nielsen, C., St. Clair, C. C. (2008): Landscape and traffic factors influencing deer-vehicle collisions in an urban environment - Humane Wildlife Conflicts 2: 102-109.

[35] Nielsen, C. K., Anderson, R. G., Grund, M. D. (2003): Landscape influences on deervehicle accident areas in an urban environment - Journal of Wildlife Management 67: 4651.

[36] Premo, D. B., Rogers, E. I. (2001): Creating and urban deer vehicle accident management plan using information from a town's GIS project. - Proceedings of the 2001 International Conference on Ecologyand Transportation, Raleigh, NC.

[37] Puglisi, M. J., Lindzey, J. S., Bellis, E. D. (1974): Factors associated with highway mortality of white-tailed deer - Journal of Wildlife Management 38: 799-807.

[38] Ramp, D., Wilson, V. K., Croft, D. B. (2006): Assessing the impacts of roads in periurban reserves: Road-based fatalities and road usage by wildlife in the Royal National Park, New South Wales, Australia - Biology Conservation 129: 348-359.

[39] Ramp, D. J., Caldwell, J., Edwards, K. A., Warton, D., Croft, D. B. (2005): Modelling of wildlife fatality hotspots along the snowy mountain highway in New South Wales Australia. Biology Conservation 126: 474-490.

[40] Reichholf, J. H. (2009): The Demise of Diversity. Loss and Extinction - Haus Publishing, London.

[41] SAS Institute Incorporated (SAS) (2012): SAS/STAT®12.1 User's Guide, Electronic book 1. - SAS Institute Inc., Cary, NC.

[42] Schippers, P., Verbroom, J., Knappen, J. P., Apeldoorn, R. C. V. (1996): Dispersal and habitat connectivity in complex heterogeneous landscapes: an analysis with a GIS-based random walk model - Ecography 19(2): 97-106.

[43] Seiler, A. (2003): The toll of the automobile: wildlife and roads in Sweden. - PhD Thesis. Swedish University of Agricultural Sciences, Uppsala, Sweden.

[44] Seiler, A. (2004): Trends and spatial patterns in ungulate-vehicle collisions in Sweden Wildlife Biology 10: 301-313.

[45] Seiler, A., Helldin, J. O., Seiler Ch. (2004): Road mortality in Swedish mammals: results of a drivers' questionnaire - Wildlife Biology 10: 225-233.

[46] Snow, N. P., Porter, W. F., Williams, D. M. (2015): Underreporting of wildlife-vehicle collisions does not hinder predictive models for large ungulates - Biology Conservation 181: 44-53.

[47] Stewart, C. M., McShea, W. J., Piccolo, B. P. (2007): The impact of white-tailed deer on agricultural landscapes in 3 national historical parks in Maryland - Journal of Wildlife Management 71(5): 1525-1530.

[48] Study of conditions and directions of spatial development of the city of Lublin, Resolution No. 283 / VIII / 2019 of the Lublin City Council of 1 July 2019.

[49] Tajchman, K., Gawryluk, A., Drozd, L., Czyżowski, P., Karpiński, M., Goleman, M. (2017a): Deer-vehicle collisions in Lubelskie region in Poland. Safety coefficients. Applied Ecology of Environmental Research 15(3): 1485-1498.

[50] Tajchman, K., Drozd, L., Karpiński, M., Czyżowski, P., Goleman, M., Chmielewski, S. (2017b): Wildlife-vehicle collisions in urban area in relations to the behaviour and density of mammals. - Polish Journal of Natural Science 32(1): 49-59.

[51] Transport Canada (2003): Overview of Technologies Aimed at Reducing and Preventing Large Animal Strikes. - Standards Research and Development Branch, Ottawa, Ontario, Canada.

[52] Trombulak, S. C., Frissell, C. A. (2000): Review of ecological effects of roads on terrestrial and aquatic communities - Conservation Biology 14(1): 18-30.

[53] Tyburski, Ł., Czerniak, A. (2013): The costs of road accidents involving animals. - Study Materials and CEPL in Rogow R.15. notebook 36/3/2013 (in Polish).

[54] Wheater, C. P. (1999)): Urban Habitats - Routledge, London and New York.

[55] Zar, J. H. (2010): Biostatistical Analysis. 5th Ed. - Prentice-Hall, Englewood Cliffs, NJ. 